\title{
Ventricular Septal Defect
}

National Cancer Institute

\section{Source}

National Cancer Institute. Ventricular Septal Defect. NCI Thesaurus. Code C84506.

The presence of a defect (opening) in the septum that separates the two ventricles of the heart. It can be congenital or acquired. 